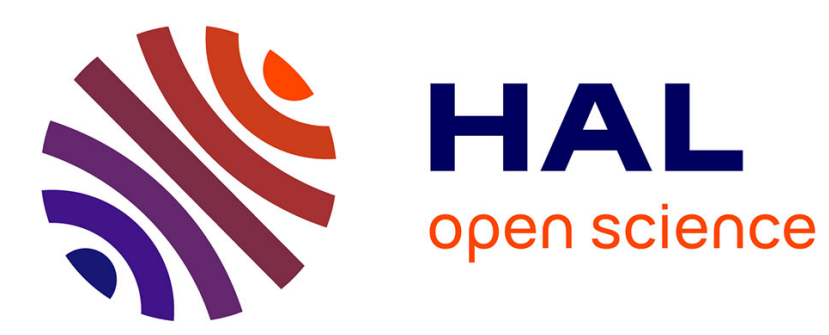

\title{
Teledermatology: The perspective of French general practitioners
}

\author{
Charbel Skayem, Hassan Rostom, Gaelle Hirsch, T.-A. Anh Duong
}

\section{To cite this version:}

Charbel Skayem, Hassan Rostom, Gaelle Hirsch, T.-A. Anh Duong. Teledermatology: The perspective of French general practitioners. Annales de Dermatologie et de Vénéréologie, In press, 10.1016/j.annder.2021.04.002 . hal-03439455

\section{HAL Id: hal-03439455 \\ https://hal.sorbonne-universite.fr/hal-03439455}

Submitted on 22 Nov 2021

HAL is a multi-disciplinary open access archive for the deposit and dissemination of scientific research documents, whether they are published or not. The documents may come from teaching and research institutions in France or abroad, or from public or private research centers.
L'archive ouverte pluridisciplinaire HAL, est destinée au dépôt et à la diffusion de documents scientifiques de niveau recherche, publiés ou non, émanant des établissements d'enseignement et de recherche français ou étrangers, des laboratoires publics ou privés. 
Teledermatology: the perspective of French general practitioners

Charbel Skayem ${ }^{1,2,3^{*}}$, Hassan Rostom ${ }^{4}$, Gaelle Hirsch ${ }^{3}$, Tu Anh Duong ${ }^{3,5.6}$

${ }^{1}$ Sorbonne Université, Faculté de médecine, Paris, France

${ }^{2}$ Université de Paris, Faculté de médecine, Paris, France

${ }^{3}$ Department of Dermatology, Assistance Publique des Hôpitaux de Paris (APHP), Henri

Mondor, France

${ }^{4}$ Cabinet médical, Bondy, France

${ }^{5}$ Chaire Avenir Santé numérique, Equipe 8 IMRB, Inserm, Université Paris Est Créteil, France

${ }^{6}$ Department of design engineering, EA 2606, Université Paris Saclay, , France

* Corresponding author :

Dr. Charbel Skayem (dermatologist and venereologist) (dermatologue et vénérologue)

-Sorbonne université, Faculté de médecine, 91 Boulevard de l'Hôpital, 75013 Paris, France

-Université de Paris, Faculté de médecine, 15 Rue de l'École de Médecine, 75006 Paris,

France

-Assistace Publique des Hôpitaux de Paris (AP-HP), Paris, France

E-mail: charbelskayem@hotmail.com 
Funding sources: None

\section{Conflicts of interest:}

Dr. Charbel Skayem and all other authors declare no conflict of interest

Keywords: teledermatology, dermatology, general physician, primary care physician, request, education

\section{Abbreviations:}

Teledermatology (TD)

General physician (GP) 
Cutaneous problems are the most common reason for consulting primary care physicians [1]. In 2012, teledermatology (TD) was integrated in the French health care system to extend access and decrease lead times for dermatological care [2]. Despite late financial remunerations in 2019 for both dermatologists and requesting physicians, several pilot programs enabled store-and-forward TD between general physicians (GPs) and dermatologists. In 2016, the dermatological emergency department of Henri Mondor University Hospital started using the TELDERM platform to provide rapid dermatological advice for non-specialist practitioners. We naturally wished to assess GPs' experience and reasons for using TD, their satisfaction and future expectations, and the challenges that TD helped them overcome.

An anonymous online survey was sent to all 94 GPs who submitting a TELDERM request from January to August 2017. The response rate was 62\% (n=58). Twenty-five GPs (43\%) had requested TD between 2 and 5 times, and 22\% more than 5 times. The reasons for use of TD were as follows: $91 \%$ to resolve diagnostic doubts, $33 \%$ for emergencies, and $64 \%$ due to long waiting times for dermatology appointments. After receiving a reply to the TD request, $98 \%$ of GPs contacted their patient to pass on the dermatologist's response, and in most cases, GPs were able to re-assess their patient. GPs very largely expressed maximum satisfaction (5/5) about the clarity of the answer given (81\%), the quick response time for proper management $(70 \%)$, and the fact that the TD procedure itself took up no additional time $(69 \%)$. Regarding future use of TD, over $50 \%$ of GPs would prefer a mobile platform, and only $36 \%$ believed that they should receive any additional fee for completing the TD request and inserting the dermatological findings. The key issues successfully resolved by TD and the numbers of GPs reporting them were as follows: providing patients with a rapid diagnosis (93\%), improving management of dermatological conditions (88\%), reducing waiting times for dermatology appointments (85\%), and providing medical education about common cutaneous diseases (71\%). 
This study was conducted before the French national insurance started reimbursing teleconsultations, although both the specialist and the requesting GP currently receive fees. Surprisingly, most physicians did not previously consider additional fees necessary, and their main use of TD was to resolve diagnostic doubts. This situation reflects the importance of including dermatology in the medical school curriculum, since GPs are regularly confronted with numerous dermatological conditions [3]. TD was very often used to overcome the impossibility of rapidly arranging a dermatology appointment, which underscores the major shortage of dermatologists in France. Serious measures need to be taken. In most cases, GPs passed on the dermatologist's response and re-assessed their patient accordingly. This shows that TD is a platform that allows follow-up when needed and emphasizes its usefulness in building patient care pathways [4]. The fact that those GPs satisfied with TD were more likely to respond might have led to overestimation of the satisfaction results. It remains important to note that TD for GPs also has limitations such as disturbance of the workflow, apprehension related to new technologies, and inadequate computer skills [5,6]. However, our findings reinforce the important role of TD in building networks between dermatologists and primary care practitioners, and in preventing diagnostic errors [3,7]. Interestingly, our findings also show that since TD enhances patient safety and GPs' dermatology management skills, financial remuneration does not appear to be the main reason for recourse to TD by GPs.

GPs are the most frequent users of TD. At a time where unexpected events are forcing us to replace in-person consultations by TD [8], it is necessary to reveal the feedback of the widest users of this approach. 
Acknowledgement: Patricia Thion 


\section{References}

[1] Schofield JK, Fleming D, Grindlay D, Williams H. Skin conditions are the commonest new reason people present to general practitioners in England and Wales. Br J Dermatol 2011;165:1044-50.

[2] Tesnière A, Leloup P, Quéreux G, Maillard H, Pedailles S, Leccia M-T, et al. Remote dermatological advice: a survey in three French regions. Ann Dermatol Venereol 2015;142:85-93.

[3] Mohan GC, Molina GE, Stavert R. Store and forward teledermatology improves dermatology knowledge among referring primary care providers: A survey-based cohort study. J Am Acad Dermatol 2018;79:960-1.

[4] McAfee JL, Vij A, Warren CB. Store-and-forward teledermatology improves care and reduces dermatology referrals from walk-in clinics: A retrospective descriptive study. J Am Acad Dermatol 2020;82:499-501.

[5] Ridard E, Secember H, Carvalho-Lallement P, Schuers M. Indicators in teledermatology: A literature review. Ann Dermatol Venereol 2020;147:602-17.

[6] Bowns IR, Collins K, Walters SJ, McDonagh AJG. Telemedicine in dermatology: a randomised controlled trial. Health Technol Assess 2006;10:iii-iv, ix-xi, 1-39. doi.org/10.3310/hta10430.

[7] Cheeley J, Chen S, Swerlick R. Consultative teledermatology in the emergency department and inpatient wards: A survey of potential referring providers. J Am Acad Dermatol 2018;79:384-6.

[8] Skayem C, Cassius C, et al. Teledermatology for COVID-19 cutaneous lesions: substitute or supplement? J Eur Acad Dermatol Venereol 2020;34:e532-3. 